\title{
Effect of Dynamic Neuromuscular Stabilization On Balance And Trunk Function In People With Multiple Sclerosis: Protocol For A Randomized Control Trial
}

\section{Laleh Abadi Marand}

Iran University of Medical Sciences

Shohreh Noorizadeh Dehkordi ( $\nabla$ noorizadeh.sh@iums.ac.ir)

Iran University of Medical Sciences https://orcid.org/0000-0002-8787-1209

Mahtab Roohi-Azizi

Iran University of Medical Sciences

Leila Janani

Iran University of Medical Sciences

Mehdi Dadgoo

Iran University of Medical Sciences

\section{Research Article}

Keywords: multiple sclerosis, balance, falling, spasticity, exercises, dynamic neuromuscular stabilization, core stability

Posted Date: May 28th, 2021

DOI: https://doi.org/10.21203/rs.3.rs-384623/v1

License: (c) (1) This work is licensed under a Creative Commons Attribution 4.0 International License. Read Full License 


\section{Abstract}

Background: Multiple sclerosis is a chronic and disabling neurological disease among young people. One of the major complaints in patients with multiple sclerosis (PWMS) is falling. There are a number of factors that cause falling, including: balance disorder and spasticity. Core stability (CS) exercises such as trunk muscle strengthening exercise can improve balance and mobility and reduce falling. Dynamic neuromuscular stabilization (DNS) exercise is a new functional rehabilitation strategy that optimizes motor function based on the principles of developmental kinesiology. This trial will evaluate the effectiveness of DNS in comparison to CS on balance, spasticity, and falling in PWMS.

Methods: A total of 66 PWMS, between 30 and 50 years old and expanded disability status scale (EDSS) between 2 to 5 , will be recruited from Tehran hospitals to participate in this 2-armed parallel study. Participants will be randomly divided into two groups to receive CS exercise or DNS exercise. All participants will receive exercise treatment for 15 sessions during a period of 5 weeks ( 3 sessions per week). Primary outcome measures will be trunk function and balance. Falling rate, fear of falling, patient mobility, as well as spasticity, will be measured as secondary outcomes. All outcome measures will be measured at baseline, the day after the completion of the $15^{\text {th }}$ session, and after three months.

Discussion: Dynamic neurostabilization exercises utilizes the subconscious stimulation of special zones to reflexively mediate the diaphragm and other core stabilization muscles, which is extremely effective for individuals with reduced somatosensory or movement awareness. Findings from the proposed study are expected to benefit the knowledge base of the physiotherapist, and it can be a good alternative for the rehabilitation program and even reduce medication use in patients with multiple sclerosis. These exercises are easy to understand and applicable for these patients and their partners as well.

Trial registration: The trial was registered in Iran registry organization with code IRCT20140222016680N5 and was approved on April $7^{\text {th }}, 2020$. Address: IRCT administration team, Central Library Building, Iran University Campus, Hemmat Freeway, next to Milad tower, Tehran, Iran. postal code:14496-14535. http://www.irct.ir/search/result?query=IRCT20140222016680N5

\section{Background}

Multiple sclerosis is a chronic neurological disease and the most important cause of non-traumatic disability among young people (1). Among the wide range of symptoms associated with multiple sclerosis, falling is one of the major complaints and a symptom experienced by more than $50 \%$ of PWMS (2). Falling causes pain, injury and fracture, and fear of falling (3). There are a number of factors that cause falling in PWMS, including: balance disorders, spasticity, and cognitive impairments (4). Living environment, using cane, fatigue, decreased muscle endurance, heat sensitivity, and urinary incontinence are the other causes of falling in PWMS $(5,6)$. Patients who have falling history walk more slowly and cautiously, and cannot correctly push their feet off the ground (7). 
Balance impairment is the most common cause of falling in PWMS with any degree of disability $(8,9)$. Individuals with multiple sclerosis have different strategies to maintain balance in comparison to healthy individuals $(10,11)$. They tend to use more compensatory postural adjustments and fewer anticipatory postural adjustments (12). Lack of trunk control and limited trunk muscle activities is one of the most important causes of balance disorders in PWMS. These patients have delayed onset times for trunk muscles, which are correlated with poor sitting balance. They have been found to have less trunk stability during arm movements compared to healthy subjects (14). As a result, they have reduced trunk dissociation between upper and lower trunk, and between trunk and lower extremity, which is one of the key factors for postural control impairment (15).

Spasticity is another common disorder in PWMS that leads to falling (16). Spasticity is said to be an annoying and disruptive factor in patient's daily living (17). It increases the likelihood of falling by increasing energy consumption, fatigue, and disturbing the patient's sleep (16). Additionally, spasticity decreases quality of life, and causes pain and disability $(17,18)$. Evidence shows that patients with neurologic disorders, such as stroke, and cerebellar palsy have less trunk control, and as a result, less capacity for elective lower limb movements $(19,20)$. Additionally, it has been shown that the trunk position affects the biomechanics of the lower extremities (21). According to Lewit and Ryerson approach, disruption of the muscle length-tension relationship, postural instability, and impairment of muscle activity pattern cause high tonocity in lower limb muscles (22). Trunk control is the strongest predictor for gait capacity in lower extremity spasticity (23), and there is a high positive correlation between trunk control and balance in patients with spastic limbs such as cerebral palsy (24).

Various studies have investigated the effect of trunk muscle training on reducing balance disorders and falling in PWMS (25-27). Core Stability (CS) training is a controlled form of exercise using the body stabilizing muscles, with emphasis on the deep abdominal muscles (28). These muscle groups are thought to contribute to trunk stability and optimal lumbar-pelvic stabilization needed for daily activities (29). CS training is recommended by international multiple sclerosis association guidelines (30), and has been commonly used for PWMS. Although CS exercises can improve balance and mobility, reduce falling rate and fear of falling in PWMS, they have no emphasis on trunk muscle timing and joint positioning (25-27). Moreover, the combination of spinal stabilization with a dyaphrgmatic breathing pattern has been missed in CS training. Dynamic neuromuscular stabilization (DNS) exercises are a new functional rehabilitation strategy that optimizes motor function based on the principles of developmental kinesiology (31). It is based on the pattern of human motor development in the early years of life that controls posture, maintains it against gravity, and activates muscles purposefully $(32,33)$. One of the most fundamental purposes of the DNS approach is to support joints and all segments into a functionally central position, at timing muscle coordination (32). In DNS, the individual must maintain the intra-abdominal pressure and perform the locomotive movement voluntarily (31). According to the evidence, DNS is an effective protocol to significantly improve respiratory function (34), and reduce forward head posture (35). It was effective in standing, walking, and jumping in patients with spastic diplegic cerebellar palsy (36), and in addition, DNS can improve trunk function, balance, and fear of falling in individuals with hemiparetic stroke (37). Thus, we hypothesize that by establishing a normal 
postural alignment and proper trunk muscle activation pattern by DNS in PWMS, balance may be improved and the tone of lower limbs can be reduced. The aim of this study is to determine the effects of DNS exercises on balance, trunk function, falling, and spasticity, and compare it with CS exercises.

\section{Methods And Design}

\section{Trial design}

This study is a 2 parallel armed, 2 parallel groups, randomized controlled trial, compared DNS exercise, to CS exercises in PWMS. This randomized controlled trial is with one to one allocation in two groups (group 1: DNS exercise, group 2: CS exercise). The time schedule of enrolment, interventions, and assessments is presented in the Table.

\section{Participants}

Women and men with multiple sclerosis aged between 30 to 50 years with moderate disabilities (EDSS between 2 and 5) will be included in the study from June 2020 to March 2021.

\section{Inclusion and exclusion criteria:}

Patients with a minimum score of 21 from the mini-mental scale examination, ability to walk, willingness to participate in the study, having sustained falling during the last three months, and at least high school graduation to filling out self-declaration questionnaires will be eligible. Patients with other neurological disorders, multiple sclerosis exacerbation during the last month, apraxia (due to inability to learn and practice the exercises), severe spasticity (score above three based on modified Ashworth scale), having a history of major surgery in the lower extremities, explicit postural abnormalities in the spine and lower limbs such as scoliosis and kyphosis and cardiovascular disease will be excluded.

\section{Recruitment procedures}

Recruitment will take place in two steps: firstly, neurologists from Tehran hospitals will identify potentially eligible patients and refer them to the research center at the School of Rehabilitation Sciences at the Iran University of Medical Sciences. Secondly, the treatment practitioner who is a physiotherapist with five years of experience in the field of neurorehabilitation will conduct another screening for inclusion and exclusion criteria and make the final decision regarding the eligibility of the patients. If eligible, the patient will be provided with oral and written information about the study. Background information including name, contact number, height and weight, medical history, and medications used will be obtained from participants. Having signed a consent form, patients will be randomized to one of the two treatment groups. This study will be conducted in a clinical setting, and the assessment will be performed in the physiotherapy evaluation laboratory in the School of Rehabilitation Sciences at the Iran University of Medical Sciences, Tehran. Treatment sessions will be performed in participants' houses because of COVID-19 pandemic.

\section{Randomization}


Permuted block randomization method with block sizes of 4 will be used for randomization. According to the sample size of 66,17 blocks will be generated using the online site (www.sealedenvelope.com).

\section{Concealment}

For concealment in the randomization process, a unique code will be used on each envelope with the group number (1 or 2) specified inside which will be done by blind analyzer.

Implication

The treatment provider will assign participants to each group.

\section{Blinding}

In this study, the assessor who evaluates the outcome of the study will be blind to the allocation of the treatment groups and doesn't provide intervention. Additionally, the data will be evaluated by an analyzer who is blind to the allocation of the participant. The analyzer will make the final decision to terminate the trial.

\section{Sample size calculation}

This study, for the first time, compares DNS exercises with CS exercises in PWMS. Due to the lack of previous studies and considering the main goal of study as comparing two groups the day after the completion of the 15th sessions, the Cohen standardized effect size for comparing means of two independent groups was used in this study to calculate the sample size. Considering the probability of the first type error of $5 \%$, the second type error of $20 \%$, and the standard Cohen's effect size of 0.8 , and using G-Power software the sample size was calculated for 26 subjects in each group which increased to 33 to assume the $20 \%$ of dropout rate. This sample size will have enough power $(0.83)$ considering effect size of 0.3 for repeated measure analysis.

\section{Interventions}

At first, necessary explanations about the importance of exercise therapy in PWMS will be given to the participants. In addition, the participants or their companions are required to make the home environment as safe as possible to minimize the likelihood of falling. In both groups, exercise sessions will be delivered three times a week, over a course of 5 weeks, and the duration of each session will be 60 to 75 minutes. In two pamphlets, both groups will be given the exercises (DNS \& CS) with the description required. In order to remind exercises to the participants, a reminder will be set on their cellphones. In addition, the participants will be instructed not to do any other exercises, nor receive other types of physiotherapy treatment, and the continuation of exercises will be recommended. If they don't want to continue the treatment sessions or female participants get pregnant during the treatment plan, they will be excluded. Four barriers to exercise in PWMS are anticipated. The first is fatigue. Rest intervals are taken between specified exercises depending on one's condition. Participants will be highly recommended to stop any exercise movement when they feel a lack of energy. The second is menstruation in women. The treatment session will be canceled on the first day of menstruation. The third is the time of the treatment session. The exercises will be performed in the morning or evening based on the participant's 
comfort and level of energy. The forth is medication. Treatment sessions will take place 48 hours after the participant's multiple sclerosis related medications.

\section{Dynamic Neuromuscular Stabilization Exercises (Group 1):}

At first, the person learns the correct posture in sitting and standing position in front of a mirror. They recognize their abdominal muscles and learn how to contract them. Then, the performer will teach participants diaphragmatic breathing.

\section{Diaphragmatic Breathing Training:}

It is recommended to sit in an erect position. The shoulders and neck should be completely relaxing, and the upper abdominal muscles should not be active. The person is asked to push the anterior and lateral walls of the abdomen out during the inhale, and perform eccentric contraction of the abdominal muscles. During exhale, they need to maintain intra-abdominal pressure with abdominal muscle contraction. Exhale time should be longer than the inhale time (32).

During each step and in every situation, diaphragmatic breathing is emphasized so that the patient follows this type of breathing in each prescribed exercise.

The exercises will be performed in four positions: supine, prone, sitting, standing as follows:

Prone position:

One turns his head to one side, bending the hand and leg on the same side, then bending the hand and opposite leg.

The shoulders and elbows in 90-90 position, lifting the chest first from the floor and then getting the elbows closer to each other and bear weight on elbows. Next, they take forearms off the ground and bear the weight on the palms of the hands, and then take the pelvic off the ground to reach the quadruped position. To separate the upper trunk from the lower trunk, move hips to each side while maintaining the upper trunk (36).

Supine position:

The thigh and knee are positioned $90-90$, and hips are slightly abducted and external rotated. The person is then asked to raise their hands to grab their knees first and then their toes. To separate the upper trunk from the lower trunk, the patient is asked to rotate the upper trunk to the left and right (without moving the lower trunk) while the arms are straight in front of the chest. Again to separate the upper trunk from the lower trunk, the lower trunk is rotated to the left and right (without moving the upper trunk) by rotating the bent knees to each side.

Simultaneous rotation of the upper trunk to one side and lower trunk to the other is the next step: changing of position from supine to side lying, with upper and lower limb flexion and adduction and trunk flexion and rotation. Then moving from side-lying to prone position while controlling the speed (36). Sitting_position: 
In long sitting position, participants put their hands out of their knees, slowly bend knees and hips, then with a slight external rotation of the hips, they try to grasp the toes. In an erect sitting position on a chair, the soles of feet on the floor, arms hooked, they rotate trunk to each side. In this position, they bend the trunk to each side to lift an object. Then they lift pelvis on each side while the trunk is fixed (37).

\section{Sit to stand transformation:}

They sit erect on the ground, one knee outward and one knee inward (side sitting). Then, with the help of a ladder, they put the foot of the in-warded knee on the ground to bring the knee forward.

In the knee-forward position, they do the forward/backward and lateral weight shifting and trunk rotation to the sides. Then bring the other leg forward and switch to Squat position, and then stand upright (31). During the first to the fifth week, the number of sets and their repetition will be increased based on one's performance.

\section{Core Stability Exercises (Group 2):}

\section{Abdominal muscles contraction}

Before starting, participants need to recognize their abdominal muscles and learn how to contract them. They will be asked to maintain abdominal contraction and normal breathing (squeeze abdomen while inhalation and exhalation) in all exercises (27).

Supine position

In supine position, participants bend their knees and put soles of both feet on the ground (crook lying). While the spine is in proper position, they pull their navel inward (squeeze abdomen gently) and maintain this condition for 5 seconds. Then, they do the same exercise with straight knee position. In crook lying position, first participants take the sole of each foot off the ground alternately, then lift both legs simultaneously and take both knees to the abdomen. As they look at the ceiling, they gently take their shoulders off the ground (curl up). Next, while both feet are on the floor, they gently flex and extend their knees (heel slide). Participants do bridging exercises while they contract their abdominal and gluteal muscles (25).

\section{Prone position}

At first, they do the abdominal contraction in the prone position. Then, they raise their chest so that they are in prone on elbow position. In the same position, they take the pelvis off the ground, while the knees and forearms are on the ground (semi plank). Next, they raise the pelvis to be in the quadruped position (26).

\section{Quadrupedposition}

In this position, they contract abdominal muscles, then they do cat-camel exercise. After that, they raise their hands then their legs alternately. In the same position, participants raise the opposite hand and leg simultaneously (27).

\section{Side-lying position}


While two knees are bent, they push the elbow on the ground to raise their trunk and pelvic off the ground (semi side bridge) (25).

Sitting.position

While sitting on a chair and soles of the feet on the floor, they raise their knees to the abdomen alternately (26).

Standing.position

As they lean against the wall, they contract abdominal muscles and gently lower the trunk as the knees bend (27).

During these five weeks, the number of the sets and their repetition will be increased based on one's performance.

\section{Outcome measures:}

All primary and secondary outcome measures will be measured by the blind assessor, who is a physiotherapy PhD student and completed a training course of biomechanical assessment tools, at baseline (a day before the first treatment session), the day after final treatment session (15th session), and at a follow-up measurement after 3 months. A home-based exercise program will be recommended for 3 months' follow-up based on their exercise group.

\section{Primary outcome measures will be:}

- Trunk function measured by the Trunk Impairment Scale

- Balance measured by the Berg Balance Scale and Biodex Balance System

\section{Trunk Impairment Scale}

The Trunk Impairment Scale is a tool to assess trunk function ability in static, dynamic, and coordination conditions, with scores ranging from zero to 23 . The scores for all items are summed, and a higher score indicates greater trunk function. In all cases, the person is in the sitting position without leaning back and without using their hands. Trunk Impairment Scale has been validated and tested for reliability in PWMS (38).

\section{Berg Balance Scale}

Berg Balance Scale is a validated tool to measure patient's static and dynamic balance. It consists of 14 items (scores from zero to 56) and is a valid and reliable test for PWMS (39). Berg Balance Scale measures balance in sitting, standing, and most daily activities (such as sitting up, moving from chair to chair, standing with eyes closed).

\section{Biodex Balance System}

Biodex Balance System SD, 115 VAC (made in the United States) is a balance system consisting of a balance plate with $20^{\circ}$ tilt range and various stability from 1 (least stable) to 12 (most stable). It is a valid and objective instrument to assesses balance performance (40). The study subjects will place their 
bare feet on the plate. Foot angle and location of the heel of each foot is recorded in the first session so that they will not change in subsequent sessions. The screen is adjusted to fit the individual height. Before starting the test, the individual will be familiarized with test's performance (postural stability and falling risk tests). Participants will be instructed to keep the black circle on the screen in the middle of the screen. The number of repetitions in each test is set to three (20 seconds each with 10 seconds to rest interval). The plate stability starts at 12 and decreases by the end of the test based on each person's ability. Overall stability, anterior-posterior and medial-lateral index, and falling risk index for each individual will be recorded.

\section{Secondary outcome measures will be:}

- Falling rate by asking the patient or their partner: "During the last 6 months, how many times have you fallen down?"

- Fear of falling by filling out Activities-specific Balance Confidence questioner.

- Patient mobility by filling out Multiple Sclerosis Walking Scale-12 questioner and measured by Time Up and Go test.

- Spasticity scale by filling out Multiple Sclerosis Spasticity Scale-88 questioner and measured by Modified Aashworth Scale.

\section{Activities-specific Balance Confidence}

Activities-specific Balance Confidence is a questioner that contains 16 items and the participant rates his or her perceived level of balance confidence for each item. Scores range from 0 to 100 (best score). It is validated for PWMS (41).

\section{Multiple Sclerosis Walking Scale-12}

The Multiple Sclerosis Walking Scale Questionnaire is a subjective questionnaire with 12 items. It is a valid and reliable scale where participants rate the extent to which multiple sclerosis has limited their walking

ability during the past 2 weeks (maximum score $=100)(42)$.

\section{Time Up and Go test}

Time Up and Go test is a valid and reliable test to measure the mobility of PWMS. The tools needed in this test are a chair with proper height, a backrest, and a stopwatch. The person sits on the chair, and 3 meters in front of the person is marked. They will be instructed to get up from the chair as quickly as possible, go up to 3 meters, turn around and follow the same path and sit on the chair. (43). The assessor records the time spent with a stopwatch. The test is repeated three times, and the average is recorded.

\section{Multiple Sclerosis Spasticity Scale-88}

Multiple Sclerosis Spasticity Scale-88 measures patient's pexperience and perception of the impact of spasticity in Multiple Sclerosis with day-to-day symptoms and during functional activities over the previous two weeks. It contains 88 questions to quantify spasticity for a total score and in eight clinically 
relevant and stand-alone subscales: muscle stiffness, pain and discomfort, muscle spasms, activities of daily living, walking, body movements, emotional health, and social functioning (44). Summation of each item score will be recorded.

\section{Modified Ashworth Scale}

Modified Ashworth Scale is the most commonly used clinical measure of spasticity. Its validity has been proven in all muscle groups. In this study, the group of knee extensors and ankle plantar flexors will be evaluated. First, the inactive range of motion of the knee and ankle joints is measured by goniometer. To measure the tone of the knee extensors, the individual sleeps in the side-lying position so that hip and knee joints are in extension and head and trunk in a straight line, and the pelvis is supported from behind. The assessor stands behind the patient, with one hand above the knee outside the thigh, which stabilizes the femur. The other hand is above the ankle. Then, for 1 second (with the word one thousand one), the knee is passively moved from maximal extension to maximal flexion. The grade ranges from 0 to 4 . To evaluate the tone of ankle plantar flexors, the person lies in the supine position, hip and knee are in extension, head and trunk in the midline. The assessor stands on the test side with one hand on the knee (to keep the lower limb fixed) and the other hand under the foot. He/she then lifts the ankle from maximum plantar flexion to maximal dorsiflexion within one second (45).

\section{Data analysis}

SPSS version 22 will be used for data analysis. Mean (standard deviation) or median (first quartile and third quartile) will be used to describe the quantitative variables according to the distribution of variables,

and for categorical variables, frequency (percentages) will be used. Graphical methods, numerical indices, and Shapiro-Wilk's tests will be used to check the normality of different measures.

To compare the mean of quantitative outcomes between two groups, independent t-test or nonparametric test, Mann-Whitney, and for within group comparisons, dependent t- test or the Wilcoxon signed-rank test will be used. Chi-squared or Fisher tests will be used to compare the categorical variables between the two groups. Repeated measure ANOVA tests will be used to compare performance at 3 months to baseline and post training performance. A 2 -tailed $\mathrm{P}<.05$ will be considered significant.

\section{Discussion}

Findings from the proposed study are expected to benefit the knowledge base of the physiotherapist, and if these exercises can reduce fall rates by lowering spasticity and improving balance, it can be a good alternative for the rehabilitation program and even reduce medication use in PWMS. Although there is various type of exercises for PWMS, they are mostly focused on balance specialized and lower limb muscles strengthening exercises which can in the short time make a difference and may not benefit the patient for a long time. As mentioned before, trunk muscle exercises such as CS exercises has been used in rehabilitation of PWMS recently. CS exercises can reduce falling rate and fear of falling and improve balance and mobility in PWMS (25-27). However, DNS was developed based on neurodevelopmental kinesiology and reflex-mediated core stabilization concepts. DNS utilizes the subconscious stimulation of 
special zones (chest zones) to reflexively mediate the diaphragm and other core stabilization muscles, which is extremely effective for individuals with reduced somatosensory or movement awareness (33). Despite the use of DNS in some disorders (34-37), there is limited evidence of effectiveness of this method in PWMS. So, the current study's aim is to compare effect of DNS to CS exercises in balance, falling and spasticity in PWMS.

Strengths of our study design include that is first randomized control trial on DNS exercises effects on PWMS. A 3- month follow up is predicted after exercise sessions. In addition, the both group of exercise packages (DNS \& CS) are easy to understand and applicable for PWMS and their partners as well. We also recognize possible limitations of the study. The inclusion criteria, preclude the majority of participants as we limit age range and EDSS. Consequently, we might encounter difficulties in finding desired participants and we may have some drop outs.

\section{Trial Status}

Enrollment of participants into this study started in June 2020 and will be completed in April 2021. Target enrollment for this study is 66 participants. Trial ID is 46429 which was approved in $7^{\text {th }}$ of April 2020 and was updated in $10^{\text {th }}$ of January 2021.

\section{Abbreviations}

Patients with Multiple Sclerosis (PWMS)

Core Stability (CS)

Dynamic Neuromuscular Stabilization (DNS)

Expanded Disability Status Scale (EDSS)

\section{Declarations}

\section{- Ethics approval and consent to participate:}

This trial gained approval from the Ethics Committee of Iran University of Medical Sciences. The approval number is IR.IUMS.REC.1398.1358 on 15th March 2020. The treatment performer (LA) obtains informed consent which will be signed and dated prior to any study-related procedures from each participant. Written consent to participate in the study is taken at the beginning of treatment sessions. Participants are able to withdraw from the trial at any time, and they will be assured that their personal information will remain confidential. Results will be presented at scientific meetings and published in peer-reviewed publications.

\section{- Consent for publication:}


“Not applicable”

\section{- Availability of data and materials:}

The datasets used and/or analyzed during the current study are available from corresponding author on reasonable request.

\section{- Competing interests:}

"Not applicable"

\section{- Funding:}

This research is supported by Iran University of Medical Sciences.

\section{- Authors' contributions:}

LAM design and drafting the work, SHND Study conception and design of the work. MRA and MD critical revision LJ Analysis and interpretation of data. All authors final approval of the version to be published.

\section{- Acknowledgements:}

This research was supported by Iran University of Medical Sciences. We would also like to show our gratitude to the Iranian association of multiple sclerosis for assistance in requirement and referring people with multiple sclerosis.

\section{References}

1. Dobson R, Giovannoni G. Multiple sclerosis-a review. European journal of neurology. 2019 Jan;26(1):27-40.

2. Cattaneo D, De Nuzzo C, Fascia T, Macalli M, Pisoni I, Cardini R. Risks of falls in subjects with multiple sclerosis. Arch Phys Med Rehabil. 2002;83(6):864-7.

3. Bazelier MT, van Staa T, Uitdehaag BM, Cooper C, Leufkens HG, Vestergaard P, Bentzen J, de Vries F. The risk of fracture in patients with multiple sclerosis: the UK general practice research. J Bone Miner Res. 2011;26(9):2271-9.

4. Hoang PD, Cameron MH, Gandevia SC, Lord SR. Neuropsychological, balance, and mobility risk factors for falls in people with multiple sclerosis: a prospective cohort study. Arch Phys Med Rehabil. 2014;95(3):480-6.

5. Gunn HJ, Newell P, Haas B, Marsden JF, Freeman JA. Identification of Risk Factors for Falls in Multiple Sclerosis: A Systematic Review and Meta-Analysis. Phys Ther. 2013;93(4):504-13.

6. Gunn H, Cameron M, Hoang P, Lord S, Shaw S, Freeman J. Relationship between physiological and perceived fall risk in people with multiple sclerosis: Implications for assessment and management. Archives of physical medicine and rehabilitation. 2018 Oct 1;99(10):2022-9. 
7. Khalil H, Al-Shorman A, El-Salem K, Abdo N, Alghwiri AA, Aburub A, Shalabi S, Al-Mustafa F. Fear of falling in people with multiple sclerosis: which clinical characteristics are important? Physical therapy. 2017 Jul 1;97(7):698-706.

8. Sosnoff JJ, Socie MJ, Boes MK, Sandroff BM, Pula JH, Suh Y, Weikert M, Balantrapu S, Morrison S, Motl RW. Mobility, balance and falls in persons with multiple sclerosis. PloS one. 2011 Nov 22;6(11): e28021.

9. Martin CL, Phillips BA, Kilpatrick TJ, Butzkueven H, Tubridy N, Mcdonald E, Galea MP. Gait and balance impairment in early multiple sclerosis in the absence of clinical disability. Mult Scler. 2006;12(5):620-8.

10. Cameron MH, Lord S. Postural control in multiple sclerosis: implications for fall prevention. Current neurology and neuroscience reports. 2010 Sep 1;10(5):407 - 12.

11. Fjeldstad C, Pardo G, Frederiksen C, Bemben D, Bemben M. Assessment of postural balance in multiple sclerosis. International Journal of MS Care. 2009;11(1):1-5.

12. Krishnan V, Kanekar N, Aruin AS. Anticipatory postural adjustments in individuals with multiple sclerosis. Neuroscience letters. 2012 Jan 11;506(2):256 - 60.

13. Freund JE, Stetts DM, Vallabhajosula S. Relationships between trunk performance, gait and postural control in persons with multiple sclerosis. NeuroRehabilitation. 2016;39(2):305-17.

14. Korkmaz NC, Akman TC, Oren GK, Bir LS. Trunk control: The essence for upper limb functionality in patients with multiple sclerosis. Multiple sclerosis and related disorders. 2018 Aug 1; 24:101-6.

15. Massot C, Simoneau-Buessinger E, Agnani O, Donze C, Leteneur S. Anticipatory postural adjustment during gait initiation in multiple sclerosis patients: A systematic review. Gait Posture. 2019 Sep;1:73:180-8.

16. Sosnoff JJ, Shin S, Motl RW. Multiple sclerosis and postural control: the role of spasticity. Arch Phys Med Rehabil. 2010;91(1):93-9.

17. Milinis K, Tennant A, Young CA, TONiC Study Group. Spasticity in multiple sclerosis: associations with impairments and overall quality of life. Mult Scler Relat Disord. 2016;5:34-9.

18. Arroyo R, Massana M, Vila C. Correlation between spasticity and quality of life in patients with multiple sclerosis: the CANDLE study. International Journal of Neuroscience. 2013 Dec 1;123(12):850-8.

19. Balzer J, Marsico P, Mitteregger E, van der Linden ML, Mercer TH, van Hedel HJ. Influence of trunk control and lower extremity impairments on gait capacity in children with cerebral palsy. Disability and rehabilitation. 2018 Dec 18;40(26):3164-70.

20. Zakaria Y, Rashad U, Mohammed R. Assessment of malalignment of trunk and pelvis in stroke patients. Egypt J Neurol Psychiat Neurosurg. 2010;47(4):599-604.

21. Blackburn JT, Padua DA. Sagittal-Plane Trunk Position, Landing Forces, and Quadriceps Electromyographic Activity. J Athl Train. 2009;44(2):174-9. 
22. Ryerson S, Levit K. Functional movement reeducation: a contemporary model for stroke rehabilitation.1st ed. Churchill Livingstone; 1997:120-250.

23. Balzer J, Marsico P, Mitteregger E, van der Linden ML, Mercer TH, van Hedel HJ. Influence of trunk control and lower extremity impairments on gait capacity in children with cerebral palsy. Disabil Rehabil. 2018;40(26):3164-70.

24. Kallem Seyyar G, Aras B, Aras O. Trunk control and functionality in children with spastic cerebral palsy. Developmental neurorehabilitation. 2019 Feb 17;22(2):120-5.

25. Carling A, Forsberg A, Gunnarsson M, Nilsagård Y. CoDuSe group exercise programme improves balance and reduces falls in people with multiple sclerosis: A multi-centre, randomized, controlled pilot study. Mult Scler. 2017;23(10):1394-404.

26. Fox EE, Hough AD, Creanor S, Gear M, Freeman JA. Effects of pilates-based core stability training in ambulant people with multiple sclerosis: multicenter, assessor-blinded, randomized controlled trial. Physical therapy. 2016 Aug 1;96(8):1170-8.

27. Freeman JA, Gear M, Pauli A, Cowan P, Finnigan C, Hunter H, Mobberley C, Nock A, Sims R, Thain J. The effect of core stability training on balance and mobility in ambulant individuals with multiple sclerosis: a multi-centre series of single case studies. Multiple Sclerosis Journal. 2010 Nov;16(11):1377-84.

28. Akuthota V, Ferreiro A, Moore T, Fredericson M. Core stability exercise principles. Current sports medicine reports. 2008 Jan 1;7(1):39-44.

29. Queiroz BC, Cagliari MF, Amorim CF, Sacco IC. Muscle activation during four Pilates core stability exercises in quadruped position. Archives of physical medicine and rehabilitation. 2010 Jan 1;91(1):86-92.

30. Motl RW, Cederberg KL, Sandroff BM. Exercise and Multiple Sclerosis: Benefits, Participation Rates, Determinants, and Opportunities. Handbook of Sport Psychology. 2020 Apr 14:857-71.

31. Frank C, Kobesova A, Kolar P. Dynamic neuromuscular stabilization \& sports rehabilitation. Int $J$ Sports Phys Ther. 2013;8(1):62-73.

32. Chaitow L, Bradley D, Gilbert Ch. Recognizing and Treating Breathing Disorders. A Multidisciplinary Approach. Churchill Livingstone. Elsevier Health Sciences. 2014:93-7.

33. Kolar P, Kobesova A, Valouchova P, Bitnar P. Dynamic neuromuscular stabilization: assessment methods. Recognizing and treating breathing disorders: A multidisciplinary approach. 2014 Jan 1:93-4.

34. Bae WS, Lee KC, Lee DY. The Effects of Dynamic Neuromuscular Stabilization Exercise on Forward Head Posture and spine Posture. Medico Legal Update. 2019 Aug 8;19(2):670-5.

35. Mohammad-Rahimi N, Mahdavinezhad R, Attarzadeh-Hosseini SR, Negahban H. Effect of Dynamic Neuromuscular Stabilization Breathing Exercises on Respiratory Function of Sedentary Students with Poor Posture. Health Education Health Promotion. 2020 Mar;10(1):19-24. 8(.

36. Son MS, Jung DH, You JS, Yi CH, Jeon HS, Cha YJ. Effects of dynamic neuromuscular stabilization on diaphragm movement, postural control, balance and gait performance in cerebral palsy. 
NeuroRehabilitation. 2017 Jan 1;41(4):739 - 46.

37. Chung EJ, Kim JH, Lee BH. The effects of core stabilization exercise on dynamic balance and gait function in stroke patients. Journal of physical therapy science. 2013;25(7):803-6.

38. Verheyden G, Nuyens G, Nieuwboer A, Van Asch P, Ketelaer P, De Weerdt W. Reliability and validity of trunk assessment for people with multiple sclerosis. Physical therapy. 2006 Jan;86(1)(1):66-76.

39. Azad A, Taghizadeh G, Khaneghini A. Assessments of the reliability of the Iranian version of the Berg Balance Scale in patients with multiple sclerosis. Acta Neurol Taiwan. 2011 Mar 1;20(1):22 - 8.

40. Cachupe WJC, Shifflett B, Kahanov L, Wughalter EH. Reliability of Biodex Balance System Measures. Meas Phys Educ Exerc Sci. 2001;5(2):97-108.

41. Nilsagård Y, Carling A, Forsberg A. Activities-specific balance confidence in people with multiple sclerosis. Multiple sclerosis international. 2012 Jan 1;1-9.

42. McGuigan $\mathrm{C}$, Hutchinson M. Confirming the validity and responsiveness of the Multiple Sclerosis Walking Scale-12 (MSWS-12). Neurology. 2004;62(11):2103-5.

43. Sebastião E, Sandroff BM, Learmonth YC, Motl RW. Validity of the timed up and go test as a measure of functional mobility in persons with multiple sclerosis. Archives of physical medicine and rehabilitation. $2016 \mathrm{Jul}$ 1;97(7):1072-7.

44. Hobart JC, Riazi A, Thompson AJ, Styles IM, Ingram W, Vickery PJ, Warner M, Fox PJ, Zajicek JP. Getting the measure of spasticity in multiple sclerosis: The Multiple Sclerosis Spasticity Scale (MSSS-88). Brain. 2005;129(1):224-34.

45. Ghotbi N, Ansari NN, Naghdi S, Hasson S. Measurement of lower-limb muscle spasticity: intrarater reliability of Modified Modified Ashworth Scale. J Rehabil Res Dev. 2011 Jan;48(1)(1):83-9.

\section{Tables}

Table 1. schedule of enrollment, intervention and assessment of PWMS. 


\begin{tabular}{|c|c|c|c|c|c|c|c|c|c|}
\hline \multirow[b]{3}{*}{ TIMEPOINT } & \multirow{3}{*}{$\begin{array}{l}\text { Enrollment } \\
\text { Week } 1\end{array}$} & \multicolumn{8}{|c|}{ STUDY PERIOD } \\
\hline & & \multirow{2}{*}{$\begin{array}{l}\text { Allocation } \\
\text { Week } 2\end{array}$} & \multicolumn{5}{|c|}{ Intervention } & \multirow{2}{*}{$\begin{array}{l}\begin{array}{l}\text { Second } \\
\text { assessme } \\
\text { nt }\end{array} \\
\begin{array}{l}\text { Week } \\
8\end{array}\end{array}$} & \multirow{2}{*}{$\begin{array}{l}\text { Follow up } \\
\text { Week } 20\end{array}$} \\
\hline & & & Weeks & $\begin{array}{l}\text { Week } \\
4\end{array}$ & $\begin{array}{l}\text { Week } \\
5\end{array}$ & $\begin{array}{l}\text { Week } \\
6\end{array}$ & $\begin{array}{l}\text { Week } \\
7\end{array}$ & & \\
\hline \multicolumn{10}{|l|}{ ENROLMENT: } \\
\hline Eligibility screen & $\mathrm{X}$ & & & & & & & & \\
\hline Informed consent & $\mathrm{X}$ & & & & & & & & \\
\hline Allocation & & $\mathrm{X}$ & & & & & & & \\
\hline \multicolumn{10}{|l|}{ INTERVENTIONS: } \\
\hline \multicolumn{10}{|l|}{ DNS (group 1) } \\
\hline \multicolumn{10}{|l|}{ CS (group 2) } \\
\hline \multicolumn{10}{|l|}{ ASSESSMENTS: } \\
\hline $\begin{array}{l}\text { Before the first } \\
\text { treatment session }\end{array}$ & & $\mathrm{X}$ & & & & & & & \\
\hline $\begin{array}{l}\text { After the last } \\
\text { treatment session }\end{array}$ & & & & & & & & $\mathrm{X}$ & \\
\hline Follow up & & & & & & & & & $\mathrm{X}$ \\
\hline
\end{tabular}

\section{Supplementary Files}

This is a list of supplementary files associated with this preprint. Click to download.

- SPIRITChecklist.doc 